\title{
Non-viral gene therapy vectors for cancer treatment
}

\author{
Shrey Kanvinde ${ }^{1,}$, Tanmay Kulkarni ${ }^{1}$, Suyash Deodhar ${ }^{2}$, Deep Bhattacharya ${ }^{1}$, Aneesha Dasgupta ${ }^{3}$
}

\author{
${ }^{1}$ Department of Pharmaceutical Sciences, University of Nebraska Medical Center, Omaha, NE \\ 68198, USA \\ ${ }^{2}$ Department of Pharmacology and Experimental Neuroscience, University of Nebraska Medical \\ Center, Omaha, NE 68198, USA \\ ${ }^{3}$ Department of Biochemistry and Molecular Biology, Mayo Clinic, Rochester, MN 55905, USA \\ * Correspondence: shreykanvinde@gmail.com
}

\begin{abstract}
The research and development of non-viral gene therapy has been extensive over the past decade and has received a big push thanks to the successful approval of non-viral gene therapy products in recent times. Despite these developments, gene therapy applications in cancer have been limited. One of the main causes of this has been the imbalance in development of delivery vectors as compared to nucleic acid payloads. This paper reviews non-viral vectors that can be used to deliver nucleic acids for cancer treatment. It discusses various types of vectors and highlights their current applications. Additionally, it also discusses perspective on regulatory landscape to facilitate commercial translation of gene therapy.
\end{abstract}

Keywords: gene therapy; non-viral vectors, cancer, gene delivery, nucleic acid delivery, nanoparticles, polymers, lipids, lipid nanoparticles, mRNA, siRNA

\section{Background}

Development of new therapies for cancer represents one of the most significant challenges in medicine. Despite significant progress in understanding the underlying mechanisms of cancer progression, there has not been a significant number of successful commercial therapies. The fiscal budget by the National Cancer Institute for 2022 mentions about $20 \%$ increase in cancer research budget, $50 \%$ increase in grants submitted which has resulted in dramatic increase in survival rates over the last decade [1]. The NCI projects about 22 million cancer survivors by 2030. Despite this, 5-year survival rates of pancreatic $(9 \%)$, lung $(7 \%)$, liver $(20 \%)$, glioblastoma $(5 \%)$ are at a dismal low. Even cancers which are responsive to treatments and have higher 5-year survival rates like breast cancer $(90 \%)$, have low treatment efficacies at later stages, leading to about 45,000 deaths in the US in 2021 (American Cancer Society. Cancer Facts $\mathcal{E}$ Figures 2021). Current non-invasive therapies utilize chemotherapeutic agents or radiation which usually results in cytotoxicity to other cells of the host body.

Genetic mutation or genome instability is an important hallmark of cancer. Mutations can be genetic or can arise spontaneously due to environmental factors. There are two kinds of genes which contain mutations - proto-oncogenes and tumor suppressors genes (TSGs) [2]. Mutations in proto-oncogenes are mainly gain of function, which lead to enhance proliferation while those in TSGs are loss of function, which lead to decreased cell death. The mutator phenotype hypothesis states that since normal mutation rates are insufficient to explain the large number of mutations, cancer cells possess increased rate of mutagenesis [3]. Mutations can occur from DNA damage or from misincorporation by DNA polymerases. These mutations are called "drivers" for their ability to progress tumorigenesis. In the past few decades, it has been reported that cancer genomes contain many additional "passenger" mutations [4]. Mutations in cancer leads to insights of its manifestation as a disease of genetic mutations. 
Based on this genetic involvement in cancer, gene therapy (GT) was proposed as a promising field which was speculated to usher in a new era of treatments. Various novel gene therapies comprising of plasmid (pDNA), messenger RNA (mRNA), oligonucleotides, and RNA interference strategies (siRNA, shRNA, miRNA) have been the most promising (Table 1), with the latter being the topic that led to Andrew Fire and Craig Mello receiving the Nobel Prize in Physiology or Medicine in 2006 [5]. GT exert their therapeutic actions may be by excising or silencing pathological genes, increasing expression of key proteins in metabolic pathways, or through targeted sequestration of proteins, cofactors, or mRNA. While pDNA remains the cornerstone of classical gene therapy, its use has been reduced to the advent of better avenues. mRNA based therapies have expanded beyond protein replacement and gene replacement in cancer treatment and have shown a meteoric rise in vaccine development against SARS-Cov-2 [6]. Additionally, mRNA therapeutics have an added advantage of better safety profile and faster protein expression compared to pDNA therapeutics since an integration of the nucleic acid cargo into the host genome is not required for expression [7]. Efforts focused on harnessing the intrinsic properties of nucleic acid drugs has led to the development of many clinically deployed nucleic acid-based therapeutics such as aptamer RNAs (e.g., pegaptanib), antisense oligonucleotides (ASOs) or antisense RNAs (asRNAs) (e.g., mipomersen, eteplirsen, nusinersen, inotersen and golodirsen), and short interfering RNAs (siRNAs) (e.g., patisiran and givosiran).

Table 1. Nucleic acid-based therapeutics

\begin{tabular}{|c|c|c|c|c|c|}
\hline Characteristics & Plasmid DNA & siRNA & shRNA & miRNA & $\begin{array}{l}\text { Antisense } \\
\text { oligonucleotide }\end{array}$ \\
\hline Properties & $\begin{array}{l}\text { Extra } \\
\text { chromosomal } \\
\text { circular DNA } \\
\text { molecules }\end{array}$ & $\begin{array}{l}\text { Double-stranded RNA } \\
\text { molecules, } 20-25 \mathrm{bp} \text { in } \\
\text { length }\end{array}$ & $\begin{array}{l}\text { Artificial RNA } \\
\text { molecule with a tight } \\
\text { hairpin turns }\end{array}$ & $\begin{array}{l}\text { Small noncoding } \\
\text { RNA molecule } \\
\text { (containing about } \\
22 \text { nucleotides }\end{array}$ & $\begin{array}{l}\text { Short strand of } \\
\text { deoxyribonucleotide } \\
\text { analog that hybridizes } \\
\text { with the } \\
\text { complementary } \\
\text { mRNA }\end{array}$ \\
\hline Molecular weight & $-0.5-5 \mathrm{kbp}$ & $19-22 \mathrm{bp}$ & 25-29 bp (stem) & 21-24 nucleotides & 18-21 nucleotides \\
\hline Mechanism of action & $\begin{array}{l}\text { Express gene } \\
\text { with } \\
\text { replacement of } \\
\text { faulty one }\end{array}$ & RNA interference & RNA interference & RNA interference & $\begin{array}{l}\text { Interfere with mRNA } \\
\text { maturation or } \\
\text { incorrect splicing in } \\
\text { the nucleus }\end{array}$ \\
\hline Advantage & $\begin{array}{l}\text { Can be used to } \\
\text { express a } \\
\text { missing gene }\end{array}$ & $\begin{array}{l}\text { Required in lower } \\
\text { amount, lower cost, and } \\
\text { toxicity }\end{array}$ & $\begin{array}{l}\text { Required in lower } \\
\text { amount, lower cost, and } \\
\text { toxicity }\end{array}$ & $\begin{array}{l}\text { Required in lower } \\
\text { amount, lower cost, } \\
\text { and toxicity }\end{array}$ & $\begin{array}{l}\text { No nuclear barrier: } \\
\text { designing is easier }\end{array}$ \\
\hline Disadvantages & $\begin{array}{l}\text { Difficult to } \\
\text { construct and } \\
\text { formulate } \\
\text { nuclear barrier }\end{array}$ & $\begin{array}{l}\text { Cannot be used to } \\
\text { express a gene of interest }\end{array}$ & $\begin{array}{l}\text { Cannot be used to } \\
\text { express a gene of } \\
\text { interest }\end{array}$ & $\begin{array}{l}\text { Cannot be used to } \\
\text { express a gene of } \\
\text { interest }\end{array}$ & $\begin{array}{l}\text { Nuclear barrier can } \\
\text { exist for some } \\
\text { therapeutic } \\
\text { applications }\end{array}$ \\
\hline Immune response & TLR9 & \multicolumn{3}{|c|}{$\begin{array}{l}\text { RNAs are generally recognized by three main types of immunoreceptors: } \\
\text { TLR, protein kinase } R \text {, and helicases }\end{array}$} & $\begin{array}{l}\text { TLR9 (if there are CPG } \\
\text { motifs in the AON } \\
\text { sequence) }\end{array}$ \\
\hline
\end{tabular}


In the past 3 decades, approximately 2000 GT trials have been conducted, two-thirds of which are in cancer therapy [8]. Cancer GT can include targeting various aspects of tumor biology such as silencing oncogenes, tumor suppressor enhancement, mutation correction and stimulation of immune cells against the tumor [9]. While the advancements made in the nucleic acid cargo have been substantial, the present challenges predominantly lie with the specific and efficient delivery of these therapeutics [10]. Free nucleotides and nucleic acids are large macromolecules that are rapidly degraded in biological microenvironments and body fluids. Secondly, owing to their bulky structure and negative charge, they have poor in vivo biodistribution and penetration across biological and cell membrane barriers. Lastly, induction of rapid immune response to sequester and subsequently degrade nucleic acids in extracellular environment also reduces the accumulation and delivery of nucleic acids to target tissues. All these factors necessitate the need of an efficient delivery system for nucleic acid payloads. An ideal delivery system must encapsulate the nucleic acid cargo, protect it from degradation, retain the macromolecular conformation of the cargo, and deliver it to a selective target tissue as well as deliver it within the appropriate cellular compartment [11]. Unfortunately, significant challenges with the development of these gene delivery vectors have resulted in an unsuccessful clinical and commercial translation. However, thanks to development of new genetic therapeutic payloads as well as novel gene delivery vehicles there has been a revival of the promise of GT in cancer treatment.

\section{Gene delivery vectors}

Gene delivery vectors can be classified into viral and non-viral vectors. Viral vectors involve replacing the virus genome with the gene of interest and then using the virus like particle to transfect at the target site [12]. Viral vectors are starting to emerge in the field, however, more work in terms of formulation and process development needs to be done [13]. In the past even though viral vectors have been shown to be stable and can withstand high temperatures, they do possess some inherent challenges in gene delivery [14]. Table 2 summarizes the different types of viral vectors along with their advantages and limitations.

Table 2. Advantages and limitations of viral gene delivery vectors

\begin{tabular}{|c|c|c|}
\hline Viral vector & Advantages & Limitations \\
\hline Lentivirus & $\begin{array}{l}\text { - Effective for long period } \\
\text { - Low host immune response }\end{array}$ & $\begin{array}{l}\text { - } 8 \mathrm{~Kb} \text { size limitation for gene } \\
\text { - In vivo transfection challenging } \\
\text { - Safety concerns }\end{array}$ \\
\hline Retrovirus & $\begin{array}{l}\text { - Can transfect difficult to transfect cells } \\
\text { - Higher safety as advanced generations self-inactivating }\end{array}$ & $\begin{array}{l}\text { - } 8 \mathrm{~Kb} \text { size limitation for gene } \\
\text { - Need active cell transport } \\
\text { - Safety concerns }\end{array}$ \\
\hline Adeno-associated virus & $\begin{array}{l}\text { - Long duration of in vivo expression } \\
\text { - Low immune response in host }\end{array}$ & $\begin{array}{l}\text { - } 4.5 \mathrm{~kb} \text { size limitation for gene } \\
\text { - Potential safety concerns of insertional mutagenesis }\end{array}$ \\
\hline Adenovirus & $\begin{array}{l}\text { - High in vivo transfection efficiency } \\
\text { - Can transfect difficult to transfect cells }\end{array}$ & $\begin{array}{l}\text { - } 7.5 \mathrm{~kb} \text { size limitation for gene } \\
\text { - Repeat dosing impossible due to immune response } \\
\text { - Short duration of in vivo transfection }\end{array}$ \\
\hline
\end{tabular}




\begin{tabular}{|l|l|l|}
\hline Herpes simplex virus & $\begin{array}{l}\text { - Effective for long period } \\
\text { - Safe in immunocompromised individuals } \\
\text { - Large insert possible }(30 \mathrm{~kb}) \\
\bullet \text { Broad cell type application }\end{array}$ & $\bullet$ Large scale production challenging \\
\hline
\end{tabular}

In contrast, non-viral vectors can overcome the immunogenicity and cytotoxicity concerns observed with viral vectors [15]. Reduced pathogenicity, in addition to low cost and ease of large-scale production, make non-viral vectors attractive gene delivery vehicles. In this review, we focus on elucidating various types of non-viral vectors utilized in gene delivery. For the ease of explanation, we have divided the vectors into carbohydrate based, polymer based, and lipid-based vectors. To conclude the review, we also touch base on the regulatory landscape and translational perspective of these vectors for gene delivery.

\section{Carbohydrate based gene delivery vehicles 3.1 Cyclodextrin based vectors}

Carbohydrates and complex polysaccharides such as cyclodextrin (CD) and chitosan have been investigated for gene delivery so far. They are combined with cationic polymers or chemically modified to impart a positive charge to form strong polyplexes with nucleic acids. They prevent the enzymatic degradation of the nucleic acid cargo by proton sponge effect resulting in endosomal swelling followed by rupture [16]. Also, CD has been shown to disrupt cellular membranes leading to increased uptake by tumor cells further potentiating EPR effect [17]. CD has been chemically conjugated to polyamidoamine (PAMAM) to generate dendrimers that are highly branched three-dimensional structures around the central core. Terminal basic amino groups form complexes with the acidic nucleic acids as shown before in the cases of siRNA and shRNA [18]. It was observed that $\alpha$ CD-PAMAM improved the transfection while protecting the siRNA from serum nucleases. Moreover, the conjugated structures were present in cytoplasm as opposed to being present in both nucleus and cytoplasm as in the case of control transfecting agents (such as LipofectamineTM2000 (L2000), RNAiFectTM (RF), and linear PEI) [19]. Later generation of complexes, $\alpha$-CD-PAMAMG3, with four degrees of folate substitution exhibited the highest intracellular delivery of siRNA in folate responsive KB cells when screened in in vitro and in vivo models [20]. The CD conjugated poly(L-lysine) dendrimer has also been employed in gene delivery. Poly(L-lysine) mimics cell penetrating peptides, increases membrane penetration, and improves gene delivery. This $\mathrm{CD}$-dendrimer system has been reported to deliver docetaxel (DOC) and matrix metalloproteinase-9 (MMP-9) siRNA. A reduction in MMP-9 levels in HNE-1 cells and higher apoptosis than DOC or plasmid individually was observed [21]. Additionally, CD-Poly(L-lysine) dendrimers conjugated with endosomal disrupting agents such as fusogenic peptides, histidine, chloroquine, etc. have been shown to further improve the transfection efficiency of siRNA. Transferrin receptors are upregulated on cancer cells to harvest iron and hence are an attractive target for gene delivery [22]. To leverage this overexpression, positively charged CD containing polymer (CDP) nanoplexes with nucleic acid have been reported. Transferrin was conjugated to CDP via PEG linker attached to adamantine inserted in CD cavity [23]. These nanoparticles have been shown to significantly inhibit tumor growth in a disseminated model of Ewing's sarcoma. Hyaluronic acid (HA) is another targeting ligand extensively used in tumor targeting since it attached to CD44 receptors overexpressed on cancer cells [13-15]. HA-PEI-CD complex showed significant improvement in transfection over PEI alone in three cancer cell lines ( 39.5, 41.4, and 8.8-fold greater in HeLa, HEK-293, and MCF-7 respectively) [16, 17]. Anisamide is a targeting functional group that binds sigma receptors on cancer cells and facilitates internalization of the nanoparticle system. A recently reported system utilized modified $C D$ with guanidino group on primary hydroxyl group. This allowed complexation with VEGF siRNA, while the secondary hydroxyl group was utilized to anchor anisamide to target sigma receptor. The authors reported 
successful reduction in VEGF mRNA levels in PC3 prostate cancer cells and significant reduction in tumor volume in TRAMP-C1 induced xenograft mouse model of prostate cancer [29]. Similarly, a system involving dilysine-CD nanoparticles, anisamide conjugated via PEG linker attached to adamantane present in CD core facilitated high cellular PLK1 siRNA uptake and corresponding PLK1 gene knockdown in prostate cancer cells. Sugars like mannose, lactose are attractive ligands for targeted gene delivery via mannose, CD205, and ASGP receptors which are overexpressed in cancer cells. Second generation of lactosylated $\alpha$-CD dendrimer (Lac- $\alpha$-CD-PAMAMG2) with 2.6 degree of substitution was found to be optimal in terms delivering pDNA in HepG2 cells via ASGP receptor. Also, glucuronylglucose modified second generation $\beta-C D$ dendrimer (GUG- $\beta$-CD-PA-

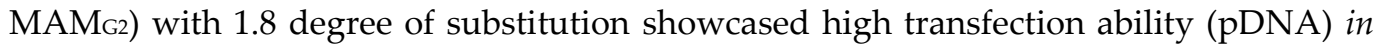
vitro (A549, RAW264.7) as well as in vivo. Folic acid decorated nanoparticles latch on to tumor cells since many cancers overexpress folate receptors and hence are used as targeting ligands for gene delivery. Nanoparticle system consisting of PEI cross-linked with 2hydroxypopyl- $\beta$-cyclodextrin (HP- $\beta$-CD) and folate improved the endocytosis of complexed VEGF siRNA demonstrating around $90 \%$ in vitro gene silencing efficiency and reduced vascular endothelial growth factor (VEGF) protein expression [30]. In vivo studies in mice demonstrated tumor growth inhibition and reduced VEGF expression in tumors. Another CD containing system for siRNA delivery against prostate specific membrane antigen (PSMA) was reported [31]. High uptake in two prostate cancer cell lines (LNCaP, VCaP) was observed. Apart from previously mentioned ligands, rabies virus glycoprotein and antibodies are additional modalities for targeted gene delivery in glioblastoma and blood cancer, respectively.

Apart from using ligands, targeted gene delivery and release can be achieved by developing gene delivery vehicles that deliver cargo upon external stimulus. These stimuli are often tumor specific environmental factors like $\mathrm{pH}$, redox state or over-expressed enzymes. Delivery vehicles take advantage of the various $\mathrm{pH}$ conditions they encounter in physiological conditions i.e., lysosomes/endosomes with acidic $\mathrm{pH}(\sim 6.0)$, tumor microenvironment with slightly acidic $\mathrm{pH}(6.5-6.8)$, and basic $\mathrm{pH}(7.4)$ in healthy tissue. Common $\mathrm{pH}$ responsive functions that are responsible for drug release include covalent bonds like hydrazine, imine, carboxyl, acetyl, cyclic orthoester, etc. A siRNA delivery system for head and neck squamous cell carcinoma was developed by incorporating a graft of three types of methacrylates attached to $\beta$-CD by acid-labile hydrazone bond [32]. A terminally located N, N, N-trimethylaminoethyl methacrylate (TMAEMA) provides positive charge responsible for siRNA complexation and forms a graft along with hydrophobic hexyl methacrylate (HMA) and pH-sensitive 2-(dimethylamino)ethyl methacrylate (DMAEMA) monomers. This system reduced mRNA and anti-apoptotic Bcl-2 protein levels in UMSCC-17B cancer cells by 50-60\% and $65-75 \%$, respectively. Tumors show a high level of glutathione (GSH) which can be harnessed to develop systems that contain redox responsive functional groups and show redox based drug release [33]. A nanoparticle system composed of poly( $\beta$-cyclodextrin) backbone and disulfide-linked poly-DMAEMA arms and auxiliary targeting system exhibited excellent pDNA transfection efficiency in $\mathrm{KB}$, HeLa, COS-7 cells [34]. The same system was also reported to exhibit gene silencing using siRNA in KB_EGFP and COS_EGFP cells. Nanoparticle systems that are triggered by external light and release gene cargo have also been reported.

Apart from their usage in conjunction with dendrimers, CDs for a supramolecular structure called polyrotaxane (PR) [35]. These are unique molecules wherein CDs are threaded and are free to rotate and slide along an axial long polymer chain that is capped at both ends by stopper groups. Upon cleavage of the stoppage groups, the CDs are released. A PR system consisting of $\alpha$-CD and PEG exhibited efficient gene knockdown by siRNA delivery in comparison to branched PEI and Lipofectamine 2000 [36]. In a separate study, PRs containing 2-hydroxypropyl- $\beta$-CD with cholesterol end caps designed for siRNA delivery showed more than $80 \%$ gene silencing in vitro (3T3-GFP, HeLa-GFP). Moreover, a $\mathrm{pH}$ responsive PR system for siRNA delivery was developed by threading $\mathrm{N}$, N-dimethylaminoethyl (DMAE) modified $\alpha$-CD segments onto PEG capped with 
bulky N-benzyloxycarbonyl-L-tyrosine groups via cleavable disulfide bonds. The siRNA mediated silencing of a firefly luciferase gene was successfully observed in HeLa cells.

\subsection{Chitosan based vectors}

Chitosan (CS) is a biodegradable and biocompatible long chain polysaccharide [37]. The primary amino groups are responsible for imparting not only positive charge in physiological conditions but also their possible versatility in terms of functionalization. Hydroxyl groups are also utilized for functionalization purposes. However, CS's high positive charge density is a driving factor behind its use as gene delivery vector. CS is modified with a hydrophobic moiety to generate an amphiphilic polymer that can be utilized for gene delivery vector development purposes. The hydrophobic moieties aid in membrane penetration and facilitate release in cytoplasm [38]. Stearic acid (SA) grafted CS was developed and studied for gene delivery applications. The screening studies with varying MW and substitution degree of polymers indicated towards the stability of vectors made of low MW polymer. Also, the size of the nanoparticle/DNA complex was large when high MW CS was used with same percent substitution degree of SA as well as high substitution degree of SA with same MW of CS. High transfection efficiency was observed in A549 cells [39]. In a separate study, a trimethylchitosan functionalized with SA by amidation of glucosamine residues through the reaction of TMC with $\mathrm{N}$-succinimidyl stearate was evaluated for splice switching oligonucleotide (SSO) delivery. A high transfection efficiency was observed in HeLa/Luc705 cells. Alternatively, linoleic acid and penetratin dual-functionalized CS generated by reacting CS with linoleic acid via EDC/NHS coupling reaction followed by carbodiimide conjugation of penetratin showed efficient protection of pDNA from DNase I attack and exhibited 34-40-fold higher transfection in comparison with unmodified chitosan in HEK 293, CHO, and HeLa cells [40]. In a separate study, folate modified linoleic acid and poly ( $\beta$-malic acid) double grafted chitosan nanoparticles were developed for the co-delivery of paclitaxel and pDNA [41]. These nanoparticles exhibited enhanced antitumor efficacy and prolonged survival period in hepatoma bearing mice. Quaternized N-(4-pyridinylmethyl) CS nanoparticles developed as delivery vectors for pDNA showed transfection efficiency in Huh 7 cells due to the 4-pyridinylmethyl substitution on CS which promoted the interaction and condensation with DNA as well as N-quaternization which increased CS water solubility [42]. CS functionalized with various imidazole moieties (imidazole acetic acid, urocanic acid, histidine) was developed keeping in mind advantages for buffering capacity, better endosomal escape, and ultimately gene transfection. Polymers with varying degrees of imidazole substitutions (5.6\%, $12.9 \%$ and $22.1 \%$ of the glucosamine) on CS were synthesized and the polyplexes formed upon DNA complexation were evaluated for $\beta$-galactosidase activity in 293T and HepG2 cells after transfection [43]. The polymer with highest substitution enhanced $\beta$-galactosidase expression. In another study, urocanic acid functionalized CS synthesized by EDC/NHS coupling reaction and complexed with DNA exhibited low cytotoxicity, high protection against nucleases, and better transfection efficiency compared to unfunctionalized CS [44]. It was also found that the transfection efficiency determined by luciferase activity in 293T cells improved as the degree of substitution increased. Histidine and CS were linked to cysteine acting as a linker by disulfide bonds [45]. Complexes prepared by histidine-modified CS with pDNA exhibited a broader buffering range, higher cellular uptake, and were more widely distributed in the cytosol suggesting the endosomal escape provided by histidine due to its high buffering capacity. The histidine functionalized CS/pDNA nanoparticles also showed higher gene expression than that of unmodified CS/pDNA complexes measured as luciferase activity in HEK293 cells. One of the studies utilized a multi-step approach that involved generation of deoxycholic acid conjugated CS followed by its complexation with siRNA in the first step [46]. The second step involved mixing of this complex in PLGA solution and emulsification in water to form nanoparticles wherein deoxycholic acid conjugated CS/siRNA complex is stabilized within polymeric PLGA. These nanoparticles exhibited improved siRNA structural stability, efficient intracellular delivery, and sustained gene silencing activity in MDA-MB- 435-GFP 
cells as measured by GFP expression. In conclusion, the gene delivery efficiency of chitosan-based delivery vectors is dependent upon various factors such as MW, degree of deacetylation, the charge ratio of chitosan to DNA/siRNA (N/P ratio), the chitosan salt form used, the DNA/siRNA concentration, $\mathrm{pH}$, serum, additives, the preparation techniques of chitosan/nucleic acid particles, and routes of administration.

\subsection{Hyaluronic acid-based vectors}

Hyaluronic acid (HA) is composed of alternating disaccharide units of D-glucuronic acid and D-N-acetylglucosamine which are linked via alternating $\beta-1,4$ and $\beta-1,3$ glycosidic bonds. Unlike chitosan, it is anionic polymer and has hydroxyl and carboxylic acid functional groups for chemical modifications to tune their physicochemical properties to achieve expected drug delivery goals [47]. It has been found that certain receptors such as CD44 and CD168 which are overexpressed in cancer cells, are natural receptors of HA. Thus, HA can be used to facilitate selective adhesion and targeted drug delivery to these cells.

\section{Polymer based vectors}

Polymers have a broad application in the fields of electronics, conductors, environmental technologies, and drug delivery has not been an exception. Within drug delivery, GT has benefited the most from polymeric delivery systems thanks to the chemically tunable nature of polymers [48]. Cationic polymers have been explored the most in nucleic acid delivery as they can associate with nucleic acids through electrostatic interactions to form polyplexes [49]. The cationic polymer must suffice several qualities for effective polyplex mediated gene delivery [50]. Amongst physical properties, the polymer should be capable of condensing the nucleic acid payloads into particles of suitable dimensions that can help accumulation into the tissue of interest. Additionally, it should be able to protect the nucleic acid from the harsh environment in the body as well as any undesired interaction with biological components. It should facilitate cell specific targeting, endosomal escape, and delivery of the nucleic acid payload at the intended site of action within the cell. Furthermore, the polymer should be nontoxic, non-immunogenic as well as biodegradable. A single polymer can rarely fulfil all these qualities and as a result, additional functional elements may have to be included within the polyplex.

Nucleic acid binding is influenced by the chemical structure of the polymer (1) number of charged groups; (2) type of charged group (primary, secondary, tertiary amines); degree of branching in the polymer, to mention a few. In addition, factors like ionic strength, concentration, N/P ratios as well as the process of polyplex formation also influence the polymer affinity to nucleic acids [51]. The type of nucleic acid affects the choice of the polymer as different nucleic acids differ in their molecular weights, number of charges as well as site of action.

Cationic polyplexes although attractive for in vitro and in vivo efficacy, suffered from drawbacks of relatively low transfection efficiency [52]. These early polycations have been explored to a great extent in literature and will not be expanded upon in this review.

The next generation of polycations were developed with a branched structure with the goal of complexing larger nucleic acid cargoes as well as showing enhanced transfection efficiency [53]. These types of polymers showed a better ability to escape endosome than early linear polycations. They are usually composed of multiple blocks of polycations that contain many proton accepting groups like amines and can achieve endosomal escape by causing an influx of chloride and water into endosome upon increased protonation in the acidic endosomal environment. This results in bursting of endosome and subsequent escape [16]. PAMAM and PEI are commonly reported polycations that exhibit proton sponge effect and are discussed in the following sections.

\subsection{PAMAM based vectors}

PAMAM dendrimers are repetitively branched structures made up of amine and amide units [54]. The amine groups are modifiable and can form complexes with a variety of 
nucleic acid payloads through electrostatic interactions [55]. Additionally, they possess qualities like high molecular uniformity, narrow molecular weight distribution as well as are biocompatible and water soluble [56]. All these factors lead to PAMAM dendrimers being efficient at gene transfer for nucleic acid drugs. There have been many generations of PAMAM dendrimers, with superior gene transfer activity observed for higher generations [57]. However, increased cytotoxicity has also been observed as the generation increased, making dendrimers with lower generation and asymmetric structure useful and displaying low cytotoxicity [58]. During the last decade the gene delivery strategies using PAMAM can be classified as (1) No surface functionalization; (2) Functionalized surface with PEG, antibodies, etc; (3) in conjugation with other delivery systems like liposomes, nanoparticles.; (4) Supramolecular self-assembly nanoparticles.

PAMAM with no surface modification represent early development work which was more focused on exploring the utility of PAMAM as a gene delivery polymer [59]. The work focused on basic biophysical analysis and looking at the cell cytotoxicity and transfection [60]. In subsequent years, modifying the PAMAM terminal amine groups became more common place, and these changes were aimed at overcoming the limitations like toxicity and limited in vivo transfection efficiency [61]. In this section we cover few recent examples of delivery systems that have leveraged modified PAMAM dendrimers and PAMAMs in conjugation with other systems either as delivery vehicle or as a functionalization. A mechanistic study by Vasumathi and co-workers looked at free energy calculations and inherent structure determination using atomistic molecular dynamics [62]. The complexation behavior was studied using siRNA and two generations of PAMAM dendrimers (G3 and G4). An increase binding energy was observed with increasing generation possibly due to increased charge ratio.

Protection of nucleic acid from biological environment is a precursor to successful delivery [63]. Abdelhady and co-workers explored the ability of flexible and rigid PAMAMs to shield siRNA from RNase degradation using atomic force microscopy [64]. Both the dendrimers showed a time dependent degradation of siRNA. However, complexes formed at lower $\mathrm{N} / \mathrm{P}$ ratio showed better resistance to siRNA degradation and reduced toxicity. An and co-workers synthesized a series of succinylated $4^{\text {th }}$ generation zwitterionic PAMAM dendrimers and investigated the role of change on DNA packaging [65]. The assembly of DNA induced by these PAMAMs was investigated using small angle Xray scattering (SAXS). They observed that higher degrees of succinylation reduced polymer-DNA interactions resulting in less stable polyplexes. Lowering the $\mathrm{pH}$ increased the charge and resulted in tighter DNA packaging. This report showed that zwitterionic PAMAMs can be used to tune polymer-DNA interactions to improve DNA packaging and engineer gene delivery vectors. Additionally, the authors also proposed that these PAMAMs would exhibit lower cytotoxicity due to reduced net charge and zwitterionic nature.

With respect to cancer applications, overcoming multidrug resistance (MDR) remains one of the biggest challenges [66]. Li and co-workers synthesized PAMAM-MDR1 siRNA (siMDR1) polyplexes surface modified with h-R3 antibody which showed reversal of MDR in breast cancer cell lines [67]. Moreover, these polyplexes worked synergistically with Paclitaxel inhibiting tumor growth and induced cell apoptosis. Also, phospholipid modified PAMAM has been shown to deliver siMDR1 to overcome MDR in human breast cancer cell lines MCF-7/ADR cells [68]. These hybrid nanoparticles could act as delivery vehicles for drug-nucleic acid or nucleic acid combinations.

As mentioned before, the latest iterations of PAMAM applications include hybrid applications where PAMAM is used in conjunction with other nanocarriers like nanoparticles, liposomes, etc) for delivering genetic material [54, 55]. Nanoparticles modified with PEG have been shown to be promising nucleic acid delivery vehicles $[56,57]$. Lim and coworkers reported PAMAM-nanodiamond hybrid nanocomplexes with E6/E7 oncoprotein siRNA for treating human papillomavirus-induced cervical cancer [73]. They showed that the nanocomplexes showed low cell cytotoxicity and significant tumor suppressing effect. 
Additionally, cellular uptake studies showed that PAMAM played a role in adjusting the $\mathrm{pH}$ to aid endosomal escape.

\subsection{Polyethylenimine (PEI) based vectors}

PEI was one of the earliest vectors which showed impressive results during in vitro transfection experiments [74]. In 1997, Baker and co-workers reported PEI as a simple and inexpensive way of condensing plasmid DNA [75]. Based on the linkages between the repeating units, PEI can be branched (bPEI) or linear(IPEI) [76]. bPEI vectors have been used to deliver DNA, RNA as well as ONs. High molecular weight bPEI up to 800KDa has been used for gene delivery applications [77]. The polyplexes formed were stable and showed higher transfection efficiency as compared to low molecular weight bPEIs. However, a corresponding decrease in cell viability was observed. This drawback could be overcome by using low molecular PEIs and increased the polymer concentration.

Although there have been a lot of reports on the use of PEI based vectors for nucleic acid delivery, very few studies have focused on mechanistic aspects [78]. GonzalezDominguez and co-workers studies the impact of physicochemical properties of DNA/PEI polyplexes on transient transfection of mammalian cells [79]. They investigated how the preparation time affects the physicochemical properties of the polyplexes and correlated it with the transfection efficiency. They used a 25kDa lPEI at a 1:2 DNA: PEI w/w ratio and with a final DNA concentration of $1 \mu \mathrm{g} / \mathrm{mL}$. The transfection was carried out in a serum-free suspension adapted HEK 293 cell line. They concluded that a strong relationship between DNA/PEI polyplex aggregation level and transfection efficiency existed. Aggregation did not affect the entire population evenly resulting in heterogenous complexes. Incubation time was a major determinant to be considered during polyplex preparation. $\mathrm{Na}$ and $\mathrm{Cl}$ concentrations were another parameter to be considered as remarkable levels of $\mathrm{Na}$ and $\mathrm{Cl}$ were detected in the particle, which probably came from the medium. Consequently, $\mathrm{NaCl}$ was indicated as a driving force for polyplex evolution in the medium as polyplexes prepared in water did not show the same transfection efficiency. SEM and TEM images also showed salt precipitates on the imaging grids. Surprisingly, the aggregates seemed to contribute significantly to transfection, probably as they carried more DNA and acted as reservoirs. Overall, this work took an interesting route towards understanding polyplex formation to improve reduce transfection variability and increasing production yield by manipulating simple parameters.

Based on literature, PEI/DNA polyplexes have been repeatedly shown to be more stable than PEI/siRNA polyplexes. Ziebarth and co-workers examined the potential causes of this difference by using molecular dynamic simulations to study complexation between PEI and nucleic acids [80]. They reported that both the types of polyplexes are stabilized by similar interactions. However, the number of interactions between PEI/DNA is greater than PEI/siRNA polyplexes with the interactions between protonated amines and DNA being particularly enhanced.

\subsection{Synthetic polymeric vectors}

The polymeric vectors discussed in the previous sections are not biodegradable and thus have no established route to leave the cells after administration. This extended exposure to foreign materials can lead to toxic effects. As a result, polymers that degrade to non-toxic or natural metabolites can enhance biocompatibility of the delivery system. Synthetic polycations can be biodegradable, enhancing their safety profile for systemic gene delivery.

Synthetic biodegradable polycations are generated by conjugating low molecular weight monomers into polymers using biodegradable or stimulus responsive linkers like sulfide or ester bonds [81]. Most explored biodegradable polycations are PLA, PGA and PLGA. They degrade via hydrolysis, thus are also sustained release materials. Of significance, PLGA has been approved by FDA [82]. PLGA-based delivery systems have been widely reported for nucleic acid payloads. Kalvanagh and co-workers reported preparation of IFN- $\lambda$ plasmid DNA encapsulated in PLGA nanoparticles [83]. They showed 
enhanced protection against DNase and increased gene delivery efficiency. Especially in delivery of siRNA, PLGA has shown a major promise as compared to PEI and PAMAMs. Risnayanti and co-workers reported evaluation of PLGA nanoparticles to co-deliver MDR1 and BCl2 siRNA to treat ovarian cancer [84]. They hypothesized that the use of these particles would overcome drug resistance. Their results demonstrate enhanced cell killing in paclitaxel and cisplatin resistant ovarian cancer cell lines. Following similar approach, $\mathrm{Su}$ and co-workers reported therapeutic efficacy of PLGA nanoparticles in co-delivering Paclitaxel and stat3 siRNA using lung cancer cell line [85]. As a next step, the surface of the PLGA nanoparticles could be decorated with ligands to enable these particles to impart target specificity to these particles. Khan and co-workers decorated the surface of PLGA nanoparticles with N-acetylgalatosamine [86]. These particles were used to encapsulate survivin siRNA and assessed for therapeutic efficacy for treatment of hepatocellular carcinoma. In a mouse model, the nanoparticle treated mice showed $75 \%$ improvement in weight loss and a significant reduction in tumor volume as compared to mice treated with free siRNA and untreated mice.

\subsection{Pharmacologically active polycations}

There have been multiple reports of pharmacologically active polycations, most of them utilizing a polycationic backbone and attaching small molecule drugs to create a polymeric drug [87]. Many groups have leveraged this strategy to attach small molecule drugs which contain primary or secondary amines to create pharmacologically active polycations that can complex nucleic acid payloads using charge interactions [88]. The resulting delivery systems can be utilized to deliver not only nucleic acid payloads but also can be designed to modulate the activity of the small molecule component. Kanvinde and coworkers reported synthesis of a polymeric chloroquine carrier [71, 72]. By modifying the small molecule drug into a macromolecular structure, they were able to modify the pharmacokinetics to suit oral route as well as systemic of delivery [73, 74]. Zhu and co-workers reported the synthesis and evaluation of self-immolative polycations that could act as both gene delivery vectors and prodrugs to target polyamine metabolism in cancer [93]. The synthesized polycation could degrade into small molecule drug Benspermine that could normalize levels of various polyamines in cancer cell resulting in cell sensitization. Additionally, the polycation could complex TNF $\alpha$ DNA and induce cell death within the sensitized cancer cells. The enhanced anti-cancer efficacy of this system was demonstrated in multiple cancer cell lines. Using the same polymeric system, Xie and co-workers showed similar findings using miR-34a microRNA [94]. Xie and co-workers also reported synthesis of a polycation using a poly (amido amine) anti-CXCR4 drug and miR-200c microRNA [95]. This polymeric system was shown to inhibit the invasiveness of cholangiocarcinoma.

\section{Lipid based vectors}

Lipids can also be used to condense and encapsulate nucleic acid payloads [96]. The major benefits of lipids include their non-toxicity, ability for easy scale-up and amenability to synthetic chemistry allowing for structural modification to bestow specificity and targeting [97]. In general, lipid structure is represented by the presence of a hydrophilic head and hydrophobic tail [98]. Moreover, the hydrophobic nature of lipids improves the payload integrity for extended periods of time [99], [100]. Overall, development of lipid vectors can be pursued by three major routes which leverage their structural characteristics [101]-

- Screening libraries of lipids to choose structurally effective for the application

- Modification of currently existing lipid to enhance transfection efficiency

- Develop new lipids to target specific target cells

The selection of lipids based on the nanoparticulate systems is usually based on selfassembly of these lipids around the nucleic acid payload in solution [102]. Based on conformation in solution, lipids can be classified as cylindrical lipids, inverse conical lipids, and conical lipids [103]. Cylindrical lipids commonly form bilayers, conical lipids form inverted micellar structures while inverse conical lipids form micelles. Self-assembly is 
also driven by modulating the polarity of the solution to harness the difference in polarity of lipid head and tail groups [104].

By either individual or a combination of these approaches and their self-assembly characteristics, various types of lipids have been developed. Various lipids have been used by themselves or in combination with other lipids to develop nanoparticulate gene delivery systems. Table 3 shows the various lipid types being currently used in lipidbased vectors.

Table 3. Types of lipids used in lipid-based gene delivery systems

\begin{tabular}{|l|l|l|l|}
\hline Type of lipid & Examples of lipids & Structural characteristics & Role in delivery systems \\
\hline Cationic lipids & DOTMA, DOTAP & $\begin{array}{l}2 \text { tails, cylindrical conformation, forms } \\
\text { bilayers, positive charged }\end{array}$ & $\begin{array}{l}\text { Forms the bilayer around the payload, major } \\
\text { structural lipid in liposome }\end{array}$ \\
\hline Ionizable cationic lipids & $\begin{array}{l}\text { DLDMA, } \\
\text { DLinDMA, }\end{array}$ & $\begin{array}{l}\text { Detween 4-6, charged at acidic } \mathrm{pH} \text { and } \\
\text { beutral at physiological pH }\end{array}$ & $\begin{array}{l}\text { Forms micellar structures around nucleic acids in } \\
\text { acidic solutions. Used in conjunction with } \\
\text { cationic and structural lipids. Major structural } \\
\text { lipid in LNPs }\end{array}$ \\
\hline Helper lipids & $\begin{array}{l}\text { Cholesterol, } \\
\text { Phosphatidylcholines }\end{array}$ & Rigid lipids & $\begin{array}{l}\text { Form anchoring regions between the structural } \\
\text { lipids and help to stabilize the lipid layer }\end{array}$ \\
\hline PEG-lipids & $\begin{array}{l}\text { PEG attached } \\
\text { cholines }\end{array}$ & $\begin{array}{l}\text { Helper lipids anchored via chemical } \\
\text { linkage to PEG }\end{array}$ & $\begin{array}{l}\text { Included to modulate the circulation time of the } \\
\text { vector. Can be diffusible or persistent depending } \\
\text { on the anchoring group }\end{array}$ \\
\hline
\end{tabular}

\subsection{Liposomes}

Liposomes are closed phospholipid vesicles with one or more concentric bilayers that form spontaneously in aqueous media and represent the earliest generation of lipid nanoparticles [105]. Lipid nanoparticles comprise of solid lipid nanoparticles that have the cargo dispersed throughout the lipid core matrix, liposomes with single or multiple phospholipid bilayer architecture, or unilayered micellar phospholipid vesicles. Among these, liposomes represent the class of delivery systems with the highest extent of clinical translation, with nine liposome-based therapeutics having received approval worldwide by respective regulatory authorities [106]. Four clinical trials for LNP based mRNA therapeutics and eight clinical trials for mRNA vaccines against cancers have been conducted [107].

Liposomes can efficiently encapsulate both hydrophilic and hydrophobic drugs and as a class have shown the most significant clinical potential in the delivery of small molecules for cancer therapy [108]. The biologically inert nature, high drug loading capacity, biocompatibility and biodegradability of liposomes make them promising candidates for drug delivery vehicles in cancer treatment $[5,6]$. Liposomes can be subjected to surface functionalization using peptides, glycans, and antibodies to actively target moieties expressed homogenously and practically exclusively in cancer cell, which have shown a higher degree of internalization [7-9]. Breast cancer associated markers like HER2 have shown a 1000-fold higher expression in tumor cells than unaffected tissue $[8,10]$. Hepatic tumor cells have also been shown to express the transferrin receptors 2.780 -fold higher compared to normal liver tissue [115]. Previous reports in the literature have reviewed the development of stealth liposomes that can evade macrophage uptake also allow for fine tuning of the metabolic fate of the cargo when delivered in vivo [8, 12]. PEGylation of liposomes allows for evasion of macrophage uptake through reduced opsonization and preventing access to bilayer surface through steric hindrance [13, 14]. Liposome can also be primed to release the nucleic acid cargo with inclusions imparting $\mathrm{pH}$ sensitivity, photosensitivity, or temperature sensitivity [15-17]. 
He and co-workers showed the therapeutic potential of liposomal CRISPR plasmid DNA coding for Cas9 and single-guide RNA targeting the ovarian cancer-related DNA methyltransferase 1 (DNMT1) gene (gDNMT1) in a murine ovarian cancer model [122]. The study also reported lower adverse events with the CRISPR therapy than a parallel paclitaxel therapy, which further highlights the advantages of this approach. Zhang and co-workers reported inhibition of lung tumor growth in BALB/c nude xenografts upon liposomal administration of anti-CYP1A1 siRNA and leading to the downregulation of CYP1A1 mRNA [123]. In a proof-of-concept study, Moitra and co-workers developed an aptamer-guided $\mathrm{pH}$ sensitive liposomal formulation to delivery plasmid DNA as well as siRNA to EpCAM overexpressing cancer stem cells [124]. Wang and co-workers developed transferrin-modified liposomes (Tf-PL) for the targeted delivery of acetylcholinesterase (AChE) gene administered subcutaneously to treat liver cancer xenografts grafted in nude mice [115]. LErafAON is a liposome encapsulated c-raf antisense oligonucleotide that reduces Raf- 1 in tumor cells, making them better primed for radiotherapy [125]. Li and co-workers utilized a more intensive human cancer xenograft models of various origins in cynomolgus monkeys to evaluate the therapeutic efficacy and safety of a cationic liposomal formulation to deliver plasmid DNA coding for mature human neutrophil peptide-1 (HNP1), albeit with injection site toxicities and heightened immune activity [126].

\subsection{Lipid Nanoparticles (LNPs)}

Onpattro represents the first clinically approved cationic liposomal formulation encapsulating siRNA to sequester and silence transthyretin for treatment in hereditary transthyretin-mediated amyloidosis [127]. The first venture of lipid-based mRNA cancer therapy was reported by Conry and co-workers in 1995, with the administration of luciferase and mRNA encoding carcinoembryonic antigen as a cancer vaccine [128]. Hou and coworkers have reviewed and summarized the clinical trials addressing the utility of lipidbased vectors in the delivery of mRNA and siRNA as vaccines and as therapeutics [107]. The most common strategy for the mRNA vaccines comprises of codelivery of antigen mRNA, and other RNA interference molecules to inhibit immune checkpoints [25, 26]. siRNA has emerged as a promising platform to inhibit tumor growth. However, this application has been limited by the various drawbacks of this nucleic acid upon administration in vivo, such as rapid enzymatic degradation, sequestration and clearance by immune cells, and poor penetrance through cell membranes [131]. However, liposomal formulations encapsulating siRNAs have shown enhanced bioavailability, better pharmacokinetic parameters, and target specificity [132]. The most employed cationic lipid architecture for delivery of mRNA and siRNA comprises of $3 \beta-\left[N-\left(N^{\prime}, N^{\prime}\right.\right.$-dimethylaminoethane)-carbamoyl] cholesterol (DC-Chol) or dimyristyloxypropyl-3-dimethyl hydroxyethyl ammonium (DMRIE), and dioleoyl phosphatidylethanolamine (DOPE) [133]. The development of ionizable cationic lipids such as DODAP (1,2-dioleoyl-3-dimethylammonium propane) has allowed the liposomes to provide high loading of negatively charged nucleic acids since the larger size of the cargo and the inability to use transmembrane $\mathrm{pH}$ gradients for loading [106]. Other cationic lipids such DOTAP (1,2-dioleoyl-3-trimethylammoniumpropane) and DOTMA (N-[1-(2,3-dioleoyloxy) propyl]-N, N, N-trimethylammonium methyl sulfate) have shown high degree of encapsulation and formulation stability upon administration in vitro and in vivo, albeit with some issues reported regarding the poor release properties of these vesicles [132]. A better selection of neutral lipids such as 1,2-dioleoyl-sn-glycero-3-phosphatidylcholine (DOPC) has shown better results in the development of siRNA based liposomal formulations for treatment of mouse xenograft tumor models [30-32]. This avenue did not show significant escalation in immune response, adverse events, or injection site toxicity upon repeated intravenous administrations, which is a common issue with viral vectors.

\subsection{Solid Lipid Nanoparticles}

Solid lipid nanoparticles (SLN) are crystallized lipid structures with a solid lipid core and an amphiphilic exterior shell. The choice of lipid composition of the SLN influences 
the overall shape of morphology of the particle, where triglyceride based SLNs have a platelet shape whereas momostearates have been shown to produce spherical particles $[33,34]$. In contrast with liposomes, SLNs care composed of solid lipids. The common approach used in the formulation of SLNs comprises of lipid acids such as mono/di/tri glycerides or waxes stabilized by ionic or non-ionic surfactants [139]. The most used lipids include hydrogenated fatty acids such as Lubritab ${ }^{\mathrm{TM}}$, Dynasan ${ }^{\mathrm{TM}}$ P60, Sterotex ${ }^{\mathrm{TM}} \mathrm{HM}$, or Lipo $^{\mathrm{TM}}$ stabilized by emulsifiers such as Pluronic F 68, F 127 [140]. While the utility of solid lipid nanoparticles (SLN) has been explored by some previous reports in the literature, they results have been mixed due to evident cytotoxicity of the cationic lipids [37, 38].

While LNPs hold potential for development as nucleic acid vectors with many advantages, so far, the clinical success of LNPs has been overshadowed by viral vectors [105]. Botto and co-workers have demonstrated the therapeutic efficacy of cationic SLN based formulations of plasmid DNA to achieve RNA interference of NUPR1-regulated genes to inhibit hepatocellular carcinoma in vitro [132]. A previous report by Mirahadi and coworkers have investigated the role and potential for SLNs in cancer diagnostics and theranostics [143].

\section{Understanding the regulatory landscape and the translational elements}

Despite the extensive research exploration on non-viral gene delivery systems, there have been many challenges for successful commercial translation. One of the major reasons for this discrepancy is the limited understanding of process development [144]. This section touches on information from FDA guidance on Chemistry, Manufacturing, and Control (CMC) Information for Human Gene Therapy Investigational New Drug Applications (INDs).

Within the United States, gene therapies are subject to oversight by two major federal agencies within the Department of Health and Human Services: (i) the Food and Drug Administration (FDA), and (ii) the Office of Biotechnology Activities (OBA) at the National Institutes of Health (NIH). Gene therapy protocols are primarily reviewed and assessed by the Recombinant DNA Advisory Committee (RAC), organized by OBA. The FDA has the legal authority to regulate gene and cell therapy products under the Investigational New Drug (IND) application, the Biologics License Application (BLA) and the Investigational Device Exemption (IDE). These regulations are found in 21 CFR 312, 21 CFR 600 and 21 CFR 800, respectively. Cancer gene therapy (CGT) products are evaluated by the Office of Cellular, Tissue and Gene Therapies (OCTGT) in the Center for Biologics Evaluation and Research (CBER). The application of current good manufacturing practices (cGMPs) is required under section Federal Food, Drug, and Cosmetic Act at all stages of clinical investigations. Recently, the FDA has issued revised guidelines for chemistry manufacturing and control of advanced medical products including gene and cell therapies. Important elements of current guidelines include detailed description of relevant critical quality attributes (CQAs) regarding safety and biological activity of the product as they are understood during the time of filing. It requires organizations to provide a detailed description of MOA of final products along with submission of information of raw materials, excipients, and intermediate process materials of the non-viral product. Details include key CMC elements such as temporary storage of bulk harvest, concentration of drug products, steps in purification, sterilization, bioburden, final non-viral drug product, and fill-finish parameters. A robust analytical testing strategy is required for manufacturers to determine identity, purity, potency, and safety of the final product [145]. Additionally, companies are required to ensure the integrity of the final drug product through strategic handling at clinical sites including shipping, storage, stability indicating methods, handling of the product at intermediate pharmacies, to dosage and administration at the clinic. While these guidelines may change from time to time, they aid to protect patients and provide transparency as the field continues to evolve to avoid some of the past missteps. Prior to initiating a phase 1 clinical trial, companies are required/encouraged to communicate with the FDA before submitting an IND for initiation of a non-viral clinical 
trial. A pre-IND meeting provides an opportunity for open dialogue between CBER/FDA and the company to discuss planned IND CMC and clinical content and obtain CBER/FDA advice to avoid any future potential clinical hold. In the current evolving field of non-viral vectors, significant process development is still required in polymer design, manufacturing components, sterile drug product, aseptic processes, cold chain supply management and many more. Development of advanced analytical technologies that enhance understanding of biophysical and biological attributes of non-viral quality attributes will be required for harmonization across the biopharmaceutical industry. Significant challenges in chemistry manufacturing and control strategy modes are still needed to be overcome to bring non-viral gene therapy to the mainstream biologic dominated market. This requires continuous improvements in understanding genome packaging in various non-viral vector systems by process and design engineering. Improvements in manufacturing alone cannot happen in isolation, it will require a consolidated effort with major companies to advance technologies in bulk substance titer control, chromatography growth, temperature control, sterile filtration, fill-finish technologies, and innovation in dosing. Finally, the regulatory landscape needs to reflect current knowledge and technologies to allow enough flexibility for the field to advance. This is particularly necessary to provide pharmaceutical scientists, academics, and clinicians ample opportunity to turn GT into mainstream medicine.

With the recent successes in multiple phases of on-going clinical trials, breakthrough siRNA-LNP by Alnylam and the commercial success of mRNA-LNPs with Pfizer and Moderna COVID vaccines, it seems likely that non-viral therapy will soon be included in the treatment armamentarium for various indications [146]. As with any drug for cancer therapy, gene therapies must meet the approval standard of being safe and effective. However, there are unique features and challenges for sponsors of gene therapies which must be addressed to continue exploration of non-viral vectors in gene delivery applications in cancer.

\section{Conclusion}

With the widespread exploration of delivery vectors for gene delivery, modulation of structure, charge, toxicity, and specificity will continue to be guiding principles. The applications of non-viral systems have diversified by development of more sophisticated nucleic acid payloads like siRNA, mRNA, microRNA as well as gene editing tools. Additionally, with frequent redosing being a probable factor in cancer therapy, non-viral vectors have added benefits over viral vectors. Advances in combination therapy of cancer from a target specificity and pharmacokinetic perspective will continue to drive development of pharmacologically active polymers. These factors, in addition the multiple clinical and commercial products are expected to result in newer generations of non-viral vectors which will be biodegradable, stimuli-responsive, target specific and safe. In combination with physical gene delivery techniques like electroporation and sonoporation, these systems can usher in a new era of genetic medicine with enhanced target effects and reduced off-target toxicity.

Author contributions. Conceptualization, S.K., T.K., S.D., D.B., A.D.; Writing - original draft preparation, review and editing, S.K., T.K., S.D., D.B., A.D. All authors have read and agreed to the published version of the manuscript.

Conflicts of interest. The authors declare no conflict of interest

\section{References}

[1] A.-I. Zaromytidou, "Reflecting on the golden age of cancer research," Nat. Cancer, vol. 2, no. 12, pp. 1271-1275, 2021, doi: 10.1038/s43018-021-00313-6. 
[2] L.-H. Wang, C.-F. Wu, N. Rajasekaran, and Y. K. Shin, “Loss of Tumor Suppressor Gene Function in Human Cancer: An Overview," Cell. Physiol. Biochem., vol. 51, no. 6, pp. 2647-2693, 2018, doi: 10.1159/000495956.

[3] J. H. Bielas, K. R. Loeb, B. P. Rubin, L. D. True, and L. A. Loeb, "Human cancers express a mutator phenotype," Proc. Natl. Acad. Sci. U. S. A., vol. 103, no. 48, pp. 18238-18242, Nov. 2006, doi: 10.1073/pnas.0607057103.

[4] C. S. J., “The paradox of mutations and cancer," Science (80-. )., vol. 362, no. 6417, pp. 893-894, Nov. 2018, doi: 10.1126/science.aav5697.

[5] S. Bajan and G. Hutvagner, "RNA-Based Therapeutics: From Antisense Oligonucleotides to miRNAs," Cells, vol. 9, no. 1, p. 137, Jan. 2020, doi: 10.3390/cells9010137.

[6] N. C. Kyriakidis, A. López-Cortés, E. V. González, A. B. Grimaldos, and E. O. Prado, "SARS-CoV-2 vaccines strategies: a comprehensive review of phase 3 candidates," npj Vaccines, vol. 6, no. 1, p. 28, 2021, doi: 10.1038/s41541-021-00292-w.

[7] A. Wadhwa, A. Aljabbari, A. Lokras, C. Foged, and A. Thakur, "Opportunities and Challenges in the Delivery of mRNA-based Vaccines," Pharmaceutics, vol. 12, no. 2, p. 102, Jan. 2020, doi: 10.3390/pharmaceutics12020102.

[8] Z. Zhou et al., "Nonviral cancer gene therapy: Delivery cascade and vector nanoproperty integration,” Adv. Drug Deliv. Rev., vol. 115, pp. 115-154, 2017, doi: https://doi.org/10.1016/j.addr.2017.07.021.

[9] J. Luo, N. L. Solimini, and S. J. Elledge, "Principles of cancer therapy: oncogene and non-oncogene addiction," Cell, vol. 136, no. 5, pp. 823-837, Mar. 2009, doi: 10.1016/j.cell.2009.02.024.

[10] M. Durymanov and J. Reineke, “Non-viral Delivery of Nucleic Acids: Insight Into Mechanisms of Overcoming Intracellular Barriers , "Frontiers in Pharmacology , vol. 9. p. 971, 2018, [Online]. Available: https://www.frontiersin.org/article/10.3389/fphar.2018.00971.

[11] A. Bolhassani and T. Saleh, "Challenges in Advancing the Field of Cancer Gene Therapy: An Overview of the Multi-Functional Nanocarriers," 2013.

[12] D. Bouard, D. Alazard-Dany, and F.-L. Cosset, "Viral vectors: from virology to transgene expression," Br. J. Pharmacol., vol. 157, no. 2, pp. 153-165, May 2009, doi: 10.1038/bjp.2008.349.

[13] A. Srivastava, K. M. G. Mallela, N. Deorkar, and G. Brophy, "Manufacturing Challenges and Rational Formulation Development for AAV Viral Vectors," J. Pharm. Sci., vol. 110, no. 7, pp. 2609-2624, 2021, doi: https://doi.org/10.1016/j.xphs.2021.03.024.

[14] R. Goswami et al., "Gene Therapy Leaves a Vicious Cycle ," Frontiers in Oncology , vol. 9. p. 297, 2019, [Online]. Available: https://www.frontiersin.org/article/10.3389/fonc.2019.00297.

[15] M. Ramamoorth and A. Narvekar, "Non viral vectors in gene therapy- an overview," J. Clin. Diagn. Res., vol. 9, no. 1, pp. GE01-GE6, Jan. 2015, doi: 10.7860/JCDR/2015/10443.5394.

[16] E. C. Freeman, L. M. Weiland, and W. S. Meng, "Modeling the proton sponge hypothesis: examining proton sponge effectiveness for enhancing intracellular gene delivery through multiscale modeling," J. Biomater. Sci. Polym. Ed., vol. 24, no. 4, pp. 398-416, 2013, doi: 10.1080/09205063.2012.690282.

[17] S. S. Jambhekar and P. Breen, "Cyclodextrins in pharmaceutical formulations I: structure and physicochemical properties, formation of complexes, and types of complex," Drug Discov. Today, vol. 21, no. 2, pp. 356-362, 2016, doi: https://doi.org/10.1016/j.drudis.2015.11.017.

[18] P. Kesharwani, K. Jain, and N. K. Jain, "Dendrimer as nanocarrier for drug delivery," Prog. Polym. Sci., vol. 39, no. 2, pp. 268-307, 2014, doi: https://doi.org/10.1016/j.progpolymsci.2013.07.005.

[19] C. Dufès, I. F. Uchegbu, and A. G. Schätzlein, "Dendrimers in gene delivery," Adv. Drug Deliv. Rev., vol. 57, no. 15, pp. 2177-2202, 2005, doi: https://doi.org/10.1016/j.addr.2005.09.017.

[20] H. Arima et al., "Folate-PEG-Appended Dendrimer Conjugate with $\alpha$-Cyclodextrin as a Novel Cancer CellSelective siRNA Delivery Carrier," Mol. Pharm., vol. 9, no. 9, pp. 2591-2604, Sep. 2012, doi: 10.1021/mp300188f. 
[21] T. Liu, W. Xue, B. Ke, M.-Q. Xie, and D. Ma, “Star-shaped cyclodextrin-poly(l-lysine) derivative co-delivering docetaxel and MMP-9 siRNA plasmid in cancer therapy," Biomaterials, vol. 35, no. 12, pp. 3865-3872, 2014, doi: https://doi.org/10.1016/j.biomaterials.2014.01.040.

[22] K. Gkouvatsos, G. Papanikolaou, and K. Pantopoulos, "Regulation of iron transport and the role of transferrin," Biochim. Biophys. Acta - Gen. Subj., vol. 1820, no. 3, pp. 188-202, 2012, doi: https://doi.org/10.1016/j.bbagen.2011.10.013.

[23] Q. Leng, M. C. Woodle, P. Y. Lu, and A. J. Mixson, "Advances in Systemic siRNA Delivery," Drugs Future, vol. 34, no. 9, p. 721, Sep. 2009, doi: 10.1358/dof.2009.034.09.1413267.

[24] D. Bhattacharya et al., "Impact of structurally modifying hyaluronic acid on CD44 interaction," J. Mater. Chem. B, vol. 5, no. 41, pp. 8183-8192, 2017, doi: 10.1039/C7TB01895A.

[25] D. S. Bhattacharya, A. Bapat, D. Svechkarev, and A. M. Mohs, “Water-Soluble Blue Fluorescent Nonconjugated Polymer Dots from Hyaluronic Acid and Hydrophobic Amino Acids," ACS Omega, vol. 6, no. 28, pp. 1789017901, Jul. 2021, doi: 10.1021/acsomega.1c01343.

[26] D. S. Bhattacharya, D. Svechkarev, A. Bapat, P. Patil, M. A. Hollingsworth, and A. M. Mohs, "Sulfation Modulates the Targeting Properties of Hyaluronic Acid to P-Selectin and CD44," ACS Biomater. Sci. Eng., vol. 6, no. 6, pp. 3585-3598, Jun. 2020, doi: 10.1021/acsbiomaterials.0c00115.

[27] S. Dehn, R. Chapman, K. A. Jolliffe, and S. Perrier, "Synthetic Strategies for the Design of Peptide/Polymer Conjugates," Polym. Rev., vol. 51, no. 2, pp. 214-234, Apr. 2011, doi: 10.1080/15583724.2011.566404.

[28] J.-F. Lutz, H. G. Börner, and K. Weichenhan, “Click Bioconjugation of a Well-Defined Synthetic Polymer and a Protein Transduction Domain," Aust. J. Chem., vol. 60, no. 6, pp. 410-413, 2007, [Online]. Available: https://doi.org/10.1071/CH07052.

[29] J. C. Evans et al., "Formulation and Evaluation of Anisamide-Targeted Amphiphilic Cyclodextrin Nanoparticles To Promote Therapeutic Gene Silencing in a 3D Prostate Cancer Bone Metastases Model," Mol. Pharm., vol. 14, no. 1, pp. 42-52, Jan. 2017, doi: 10.1021/acs.molpharmaceut.6b00646.

[30] H. Arima, K. Motoyama, and T. Higashi, "Polyamidoamine Dendrimer Conjugates with Cyclodextrins as Novel Carriers for DNA, shRNA and siRNA," Pharmaceutics, vol. 4, no. 1, pp. 130-148, Feb. 2012, doi: 10.3390/pharmaceutics4010130.

[31] J.-M. Li, Y.-Y. Wang, W. Zhang, H. Su, L.-N. Ji, and Z.-W. Mao, "Low-weight polyethylenimine cross-linked 2hydroxypopyl- $\beta$-cyclodextrin and folic acid as an efficient and nontoxic siRNA carrier for gene silencing and tumor inhibition by VEGF siRNA," Int. J. Nanomedicine, vol. 8, pp. 2101-2117, 2013, doi: 10.2147/IJN.S42440.

[32] J. C. Evans et al., "Folate-targeted amphiphilic cyclodextrin.siRNA nanoparticles for prostate cancer therapy exhibit PSMA mediated uptake, therapeutic gene silencing in vitro and prolonged circulation in vivo," Nanomedicine Nanotechnology, Biol. Med., vol. 12, no. 8, pp. 2341-2351, 2016, doi: https://doi.org/10.1016/j.nano.2016.06.014.

[33] N. Traverso et al., "Role of glutathione in cancer progression and chemoresistance," Oxid. Med. Cell. Longev., vol. 2013, p. 972913, 2013, doi: 10.1155/2013/972913.

[34] W.-F. Lai, “Cyclodextrins in non-viral gene delivery," Biomaterials, vol. 35, no. 1, pp. 401-411, Jan. 2014, doi: 10.1016/j.biomaterials.2013.09.061.

[35] G. Wenz, B.-H. Han, and A. Müller, “Cyclodextrin Rotaxanes and Polyrotaxanes," Chem. Rev., vol. 106, no. 3, pp. 782-817, Mar. 2006, doi: 10.1021/cr970027+.

[36] A. Kulkarni et al., "Cationic $\alpha$-Cyclodextrin:Poly(ethylene glycol) Polyrotaxanes for siRNA Delivery," Mol. Pharm., vol. 10, no. 4, pp. 1299-1305, Apr. 2013, doi: 10.1021/mp300449t.

[37] Y. Cao, Y. F. Tan, Y. S. Wong, M. W. J. Liew, and S. Venkatraman, “Recent Advances in Chitosan-Based Carriers 
for Gene Delivery," Mar. Drugs, vol. 17, no. 6, p. 381, Jun. 2019, doi: 10.3390/md17060381.

[38] K. A. Janes, P. Calvo, and M. J. Alonso, "Polysaccharide colloidal particles as delivery systems for macromolecules," Adv. Drug Deliv. Rev., vol. 47, no. 1, pp. 83-97, 2001, doi: https://doi.org/10.1016/S0169409X(00)00123-X.

[39] F.-Q. Hu, M.-D. Zhao, H. Yuan, J. You, Y.-Z. Du, and S. Zeng, "A novel chitosan oligosaccharide-stearic acid micelles for gene delivery: Properties and in vitro transfection studies," Int. J. Pharm., vol. 315, no. 1, pp. 158-166, 2006, doi: https://doi.org/10.1016/j.ijpharm.2006.02.026.

[40] B. Layek and J. Singh, “Cell Penetrating Peptide Conjugated Polymeric Micelles as a High Performance Versatile Nonviral Gene Carrier," Biomacromolecules, vol. 14, no. 11, pp. 4071-4081, Nov. 2013, doi: 10.1021/bm401204n.

[41] B. Yu, C. Tang, and C. Yin, "Enhanced antitumor efficacy of folate modified amphiphilic nanoparticles through co-delivery of chemotherapeutic drugs and genes," Biomaterials, vol. 35, no. 24, pp. 6369-6378, 2014, doi: https://doi.org/10.1016/j.biomaterials.2014.04.095.

[42] P. Opanasopit, W. Sajomsang, U. Ruktanonchai, V. Mayen, T. Rojanarata, and T. Ngawhirunpat, “Methylated N-(4-pyridinylmethyl) chitosan as a novel effective safe gene carrier," Int. J. Pharm., vol. 364, no. 1, pp. 127-134, 2008, doi: https://doi.org/10.1016/j.ijpharm.2008.08.003.

[43] C. Moreira, H. Oliveira, L. R. Pires, S. Simões, M. A. Barbosa, and A. P. Pêgo, “Improving chitosan-mediated gene transfer by the introduction of intracellular buffering moieties into the chitosan backbone," Acta Biomater., vol. 5, no. 8, pp. 2995-3006, 2009, doi: https://doi.org/10.1016/j.actbio.2009.04.021.

[44] T. H. Kim, J. E. Ihm, Y. J. Choi, J. W. Nah, and C. S. Cho, “Efficient gene delivery by urocanic acid-modified chitosan," J. Control. Release, vol. 93, no. 3, pp. 389-402, 2003, doi: https://doi.org/10.1016/j.jconrel.2003.08.017.

[45] K.-L. Chang, Y. Higuchi, S. Kawakami, F. Yamashita, and M. Hashida, “Efficient Gene Transfection by HistidineModified Chitosan through Enhancement of Endosomal Escape," Bioconjug. Chem., vol. 21, no. 6, pp. 1087-1095, Jun. 2010, doi: 10.1021/bc1000609.

[46] J. Y. Lee, S. H. Lee, M. H. Oh, J. S. Kim, T. G. Park, and Y. S. Nam, "Prolonged gene silencing by siRNA/chitosang-deoxycholic acid polyplexes loaded within biodegradable polymer nanoparticles," J. Control. Release, vol. 162, no. 2, pp. 407-413, 2012, doi: https://doi.org/10.1016/j.jconrel.2012.07.006.

[47] K. Liu, X. Jiang, and P. Hunziker, "Carbohydrate-based amphiphilic nano delivery systems for cancer therapy," Nanoscale, vol. 8, no. 36, pp. 16091-16156, 2016, doi: 10.1039/c6nr04489a.

[48] J. W. Salameh, L. Zhou, S. M. Ward, C. F. Santa Chalarca, T. Emrick, and M. L. Figueiredo, "Polymer-mediated gene therapy: Recent advances and merging of delivery techniques," Wiley Interdiscip. Rev. Nanomed. Nanobiotechnol., vol. 12, no. 2, pp. e1598-e1598, Mar. 2020, doi: 10.1002/wnan.1598.

[49] E. Wagner, "Chapter Eight - Polymers for Nucleic Acid Transfer-An Overview," in Nonviral Vectors for Gene Therapy, vol. 88, L. Huang, D. Liu, and E. B. T.-A. in G. Wagner, Eds. Academic Press, 2014, pp. $231-261$.

[50] A. S. Piotrowski-Daspit, A. C. Kauffman, L. G. Bracaglia, and W. M. Saltzman, "Polymeric vehicles for nucleic acid delivery," Adv. Drug Deliv. Rev., vol. 156, pp. 119-132, 2020, doi: https://doi.org/10.1016/j.addr.2020.06.014.

[51] M. X. Tang and F. C. Szoka, "The influence of polymer structure on the interactions of cationic polymers with DNA and morphology of the resulting complexes," Gene Ther., vol. 4, no. 8, pp. 823-832, 1997, doi: 10.1038/sj.gt.3300454.

[52] A. Hall, U. Lächelt, J. Bartek, E. Wagner, and S. M. Moghimi, "Polyplex Evolution: Understanding Biology, Optimizing Performance," Mol. Ther., vol. 25, no. 7, pp. 1476-1490, 2017, doi: https://doi.org/10.1016/j.ymthe.2017.01.024.

[53] M. Thomas and A. M. Klibanov, "Enhancing polyethylenimine's delivery of plasmid DNA into mammalian cells," Proc. Natl. Acad. Sci. U. S. A., vol. 99, no. 23, pp. 14640-14645, Nov. 2002, doi: 10.1073/pnas.192581499. 
[54] P. K. Maiti, T. Çağın, G. Wang, and W. A. Goddard, "Structure of PAMAM Dendrimers: Generations 1 through 11," Macromolecules, vol. 37, no. 16, pp. 6236-6254, Aug. 2004, doi: 10.1021/ma035629b.

[55] F. Abedi-Gaballu et al., "PAMAM dendrimers as efficient drug and gene delivery nanosystems for cancer therapy," Appl. Mater. today, vol. 12, pp. 177-190, Sep. 2018, doi: 10.1016/j.apmt.2018.05.002.

[56] R. V. de Araújo, S. da S. Santos, E. Igne Ferreira, and J. Giarolla, “New Advances in General Biomedical Applications of PAMAM Dendrimers," Molecules, vol. 23, no. 11, p. 2849, Nov. 2018, doi: 10.3390/molecules23112849.

[57] N. Bono et al., "Role of Generation on Successful DNA Delivery of PAMAM-(Guanidino)Neomycin Conjugates," ACS Omega, vol. 4, no. 4, pp. 6796-6807, Apr. 2019, doi: 10.1021/acsomega.8b02757.

[58] A. A. Chis et al., "Applications and Limitations of Dendrimers in Biomedicine," Molecules, vol. 25, no. 17, p. 3982, Sep. 2020, doi: 10.3390/molecules25173982.

[59] P. Kesharwani et al., "PAMAM dendrimers as promising nanocarriers for RNAi therapeutics," Mater. Today, vol. 18, no. 10, pp. 565-572, 2015, doi: https://doi.org/10.1016/j.mattod.2015.06.003.

[60] A. S. Chauhan, "Dendrimers for Drug Delivery," Molecules, vol. 23, no. 4, p. 938, Apr. 2018, doi: 10.3390/molecules23040938.

[61] A. Janaszewska, J. Lazniewska, P. Trzepiński, M. Marcinkowska, and B. Klajnert-Maculewicz, “Cytotoxicity of Dendrimers," Biomolecules, vol. 9, no. 8, p. 330, Aug. 2019, doi: 10.3390/biom9080330.

[62] V. Vasumathi and P. K. Maiti, "Complexation of siRNA with Dendrimer: A Molecular Modeling Approach," Macromolecules, vol. 43, no. 19, pp. 8264-8274, Oct. 2010, doi: 10.1021/ma1012495.

[63] H. C. Kang, K. M. Huh, and Y. H. Bae, "Polymeric nucleic acid carriers: current issues and novel design approaches," J. Control. Release, vol. 164, no. 3, pp. 256-264, Dec. 2012, doi: 10.1016/j.jconrel.2012.06.036.

[64] H. G. Abdelhady, S. Allen, M. C. Davies, C. J. Roberts, S. J. B. Tendler, and P. M. Williams, “Atomic force microscopy studies of generation 4 poly(amidoamine) (PAMAM) dendrimers on functionalized surfaces," Surf. Sci., vol. 558, no. 1, pp. 99-110, 2004, doi: https://doi.org/10.1016/j.susc.2004.03.049.

[65] M. An, G. Y. Tonga, S. R. Parkin, V. M. Rotello, and J. E. DeRouchey, “Tuning DNA Condensation with Zwitterionic Polyamidoamine (zPAMAM) Dendrimers," Macromolecules, vol. 50, no. 20, pp. 8202-8211, Oct. 2017, doi: 10.1021/acs.macromol.7b01470.

[66] J.-P. Gillet and M. M. Gottesman, "Mechanisms of Multidrug Resistance in Cancer BT - Multi-Drug Resistance in Cancer," J. Zhou, Ed. Totowa, NJ: Humana Press, 2010, pp. 47-76.

[67] J. Li, H. Liang, J. Liu, and Z. Wang, "Poly (amidoamine) (PAMAM) dendrimer mediated delivery of drug and pDNA/siRNA for cancer therapy," Int. J. Pharm., vol. 546, no. 1, pp. 215-225, 2018, doi: https://doi.org/10.1016/j.ijpharm.2018.05.045.

[68] J. Liu et al., "In vitro studies of phospholipid-modified PAMAM-siMDR1 complexes for the reversal of multidrug resistance in human breast cancer cells," Int. J. Pharm., vol. 530, no. 1, pp. 291-299, 2017, doi: https://doi.org/10.1016/j.ijpharm.2017.06.026.

[69] E. R. Figueroa, A. Y. Lin, J. Yan, L. Luo, A. E. Foster, and R. A. Drezek, “Optimization of PAMAM-gold nanoparticle conjugation for gene therapy," Biomaterials, vol. 35, no. 5, pp. 1725-1734, Feb. 2014, doi: 10.1016/j.biomaterials.2013.11.026.

[70] I. Tariq et al., "Lipodendriplexes mediated enhanced gene delivery: a cellular to pre-clinical investigation," Sci. Rep., vol. 10, no. 1, p. 21446, 2020, doi: 10.1038/s41598-020-78123-6.

[71] A. Wani et al., "Surface PEGylation of Mesoporous Silica Nanorods (MSNR): Effect on loading, release, and delivery of mitoxantrone in hypoxic cancer cells," Sci. Rep., vol. 7, no. 1, p. 2274, 2017, doi: 10.1038/s41598-01702531-4. 
[72] R. Roggers, S. Kanvinde, S. Boonsith, and D. Oupický, "The practicality of mesoporous silica nanoparticles as drug delivery devices and progress toward this goal," AAPS PharmSciTech, vol. 15, no. 5, pp. 1163-1171, Oct. 2014, doi: 10.1208/s12249-014-0142-7.

[73] D. G. Lim et al., "Polyamidoamine-Decorated Nanodiamonds as a Hybrid Gene Delivery Vector and siRNA Structural Characterization at the Charged Interfaces," ACS Appl. Mater. Interfaces, vol. 9, no. 37, pp. 31543-31556, Sep. 2017, doi: 10.1021/acsami.7b09624.

[74] R. M. Cordes, W. B. Sims, and C. E. Glatz, "Precipitation of Nucleic Acids with Poly (ethyleneimine)," Biotechnol. Prog., vol. 6, no. 4, pp. 283-285, Jul. 1990, doi: https://doi.org/10.1021/bp00004a009.

[75] A. Baker et al., "Polyethylenimine (PEI) is a simple, inexpensive and effective reagent for condensing and linking plasmid DNA to adenovirus for gene delivery," Gene Ther., vol. 4, no. 8, pp. 773-782, 1997, doi: 10.1038/sj.gt.3300471.

[76] J. W. Wiseman, C. A. Goddard, D. McLelland, and W. H. Colledge, "A comparison of linear and branched polyethylenimine (PEI) with DCChol/DOPE liposomes for gene delivery to epithelial cells in vitro and in vivo," Gene Ther., vol. 10, no. 19, pp. 1654-1662, 2003, doi: 10.1038/sj.gt.3302050.

[77] L. Wightman et al., "Different behavior of branched and linear polyethylenimine for gene delivery in vitro and in vivo," J. Gene Med., vol. 3, no. 4, pp. 362-372, Jul. 2001, doi: https://doi.org/10.1002/jgm.187.

[78] A. Kichler, C. Leborgne, E. Coeytaux, and O. Danos, "Polyethylenimine-mediated gene delivery: a mechanistic study," J. Gene Med., vol. 3, no. 2, pp. 135-144, Mar. 2001, doi: https://doi.org/10.1002/jgm.173.

[79] I. González-Domínguez, N. Grimaldi, L. Cervera, N. Ventosa, and F. Gòdia, "Impact of physicochemical properties of DNA/PEI complexes on transient transfection of mammalian cells," N. Biotechnol., vol. 49, pp. 8897, 2019, doi: https://doi.org/10.1016/j.nbt.2018.09.005.

[80] J. D. Ziebarth, D. R. Kennetz, N. J. Walker, and Y. Wang, "Structural Comparisons of PEI/DNA and PEI/siRNA Complexes Revealed with Molecular Dynamics Simulations," J. Phys. Chem. B, vol. 121, no. 8, pp. 1941-1952, Mar. 2017, doi: 10.1021/acs.jpcb.6b10775.

[81] N. Kamaly, B. Yameen, J. Wu, and O. C. Farokhzad, “Degradable Controlled-Release Polymers and Polymeric Nanoparticles: Mechanisms of Controlling Drug Release," Chem. Rev., vol. 116, no. 4, pp. 2602-2663, Feb. 2016, doi: 10.1021/acs.chemrev.5b00346.

[82] J.-M. Lü et al., "Current advances in research and clinical applications of PLGA-based nanotechnology," Expert Rev. Mol. Diagn., vol. 9, no. 4, pp. 325-341, May 2009, doi: 10.1586/erm.09.15.

[83] P. Amir Kalvanagh, M. Ebtekara, P. Kokhaei, and H. Soleimanjahi, "Preparation and Characterization of PLGA Nanoparticles Containing Plasmid DNA Encoding Human IFN-lambda-1/IL-29," Iran. J. Pharm. Res. IJPR, vol. 18, no. 1, pp. 156-167, 2019, [Online]. Available: https://pubmed.ncbi.nlm.nih.gov/31089352.

[84] C. Risnayanti, Y.-S. Jang, J. Lee, and H. J. Ahn, "PLGA nanoparticles co-delivering MDR1 and BCL2 siRNA for overcoming resistance of paclitaxel and cisplatin in recurrent or advanced ovarian cancer," Sci. Rep., vol. 8, no. 1, p. 7498, May 2018, doi: 10.1038/s41598-018-25930-7.

[85] W.-P. Su, F.-Y. Cheng, D.-B. Shieh, C.-S. Yeh, and W.-C. Su, "PLGA nanoparticles codeliver paclitaxel and Stat3 siRNA to overcome cellular resistance in lung cancer cells," Int. J. Nanomedicine, vol. 7, pp. 4269-4283, 2012, doi: 10.2147/IJN.S33666.

[86] A. A. Khan, A. M. Alanazi, M. Jabeen, A. Chauhan, and M. A. Ansari, "Therapeutic potential of functionalized siRNA nanoparticles on regression of liver cancer in experimental mice," Sci. Rep., vol. 9, no. 1, p. 15825, Nov. 2019, doi: 10.1038/s41598-019-52142-4.

[87] I. Vroman and L. Tighzert, “Biodegradable Polymers,” Materials (Basel)., vol. 2, no. 2, pp. 307-344, Apr. 2009, doi: 10.3390/ma2020307. 
[88] J. Li, F. Yu, Y. Chen, and D. Oupický, "Polymeric drugs: Advances in the development of pharmacologically active polymers," J. Control. Release, vol. 219, pp. 369-382, Dec. 2015, doi: 10.1016/j.jconrel.2015.09.043.

[89] S. Kanvinde, "Development of Novel Therapies for the Treatment of Inflammatory Bowel Disease," 2018.

[90] S. Kanvinde et al., "Pharmacokinetics and efficacy of orally administered polymeric chloroquine as macromolecular drug in the treatment of inflammatory bowel disease," Acta Biomater., vol. 82, pp. 158-170, Dec. 2018, doi: 10.1016/j.actbio.2018.10.027.

[91] Y. S. Chhonker, S. Kanvinde, R. Ahmad, A. B. Singh, D. Oupický, and D. J. Murry, "Simultaneous Quantitation of Lipid Biomarkers for Inflammatory Bowel Disease Using LC-MS/MS," Metabolites , vol. 11, no. 2. 2021, doi: 10.3390/metabo11020106.

[92] R. Sleightholm, "Degradable and non-degradable polymeric chloroquine: Altering chloroquine's pharmacokinetics for translational improvements in inflammatory bowel disease and cancer," in Clinical Pharmacology \& Therapeutics, 2018, pp. S50-S51.

[93] Y. Zhu et al., "Self-immolative polycations as gene delivery vectors and prodrugs targeting polyamine metabolism in cancer," Mol. Pharm., vol. 12, no. 2, pp. 332-341, Feb. 2015, doi: 10.1021/mp500469n.

[94] Y. Xie et al., "Self-immolative nanoparticles for simultaneous delivery of microRNA and targeting of polyamine metabolism in combination cancer therapy," J. Control. Release, vol. 246, pp. 110-119, Jan. 2017, doi: 10.1016/j.jconrel.2016.12.017.

[95] Y. Xie et al., "Delivery of miR-200c Mimic with Poly(amido amine) CXCR4 Antagonists for Combined Inhibition of Cholangiocarcinoma Cell Invasiveness," Mol. Pharm., vol. 13, no. 3, pp. 1073-1080, Mar. 2016, doi: 10.1021/acs.molpharmaceut.5b00894.

[96] Y. Zhao and L. Huang, "Lipid nanoparticles for gene delivery," Adv. Genet., vol. 88, pp. 13-36, 2014, doi: 10.1016/B978-0-12-800148-6.00002-X.

[97] J. Buck, P. Grossen, P. R. Cullis, J. Huwyler, and D. Witzigmann, “Lipid-Based DNA Therapeutics: Hallmarks of Non-Viral Gene Delivery," ACS Nano, vol. 13, no. 4, pp. 3754-3782, Apr. 2019, doi: 10.1021/acsnano.8b07858.

[98] S. Bhattacharya and A. Bajaj, "Advances in gene delivery through molecular design of cationic lipids," Chem. Commun., no. 31, pp. 4632-4656, 2009, doi: 10.1039/B900666B.

[99] T. A. Kulkarni et al., "A year-long extended release nanoformulated cabotegravir prodrug," Nat. Mater., vol. 19, no. 8, pp. 910-920, 2020, doi: 10.1038/s41563-020-0674-z.

[100] N. Gautam et al., "Lipophilic nanocrystal prodrug-release defines the extended pharmacokinetic profiles of a year-long cabotegravir," Nat. Commun., vol. 12, no. 1, p. 3453, 2021, doi: 10.1038/s41467-021-23668-x.

[101] A. Akinc et al., "The Onpattro story and the clinical translation of nanomedicines containing nucleic acid-based drugs," Nat. Nanotechnol., vol. 14, no. 12, pp. 1084-1087, 2019, doi: 10.1038/s41565-019-0591-y.

[102] J. N. Israelachvili, D. J. Mitchell, and B. W. Ninham, "Theory of self-assembly of lipid bilayers and vesicles," Biochim. Biophys. Acta - Biomembr., vol. 470, no. 2, pp. 185-201, 1977, doi: https://doi.org/10.1016/00052736(77)90099-2.

[103] C. Peetla, S. Vijayaraghavalu, and V. Labhasetwar, "Biophysics of cell membrane lipids in cancer drug resistance: Implications for drug transport and drug delivery with nanoparticles," Adv. Drug Deliv. Rev., vol. 65, no. 13, pp. 1686-1698, 2013, doi: https://doi.org/10.1016/j.addr.2013.09.004.

[104] N. M. Belliveau et al., "Microfluidic Synthesis of Highly Potent Limit-size Lipid Nanoparticles for In Vivo Delivery of siRNA," Mol. Ther. - Nucleic Acids, vol. 1, p. e37, 2012, doi: https://doi.org/10.1038/mtna.2012.28.

[105] R. Tenchov, R. Bird, A. E. Curtze, and Q. Zhou, "Lipid Nanoparticles-From Liposomes to mRNA Vaccine Delivery, a Landscape of Research Diversity and Advancement," ACS Nano, vol. 15, no. 11, pp. 16982-17015, Nov. 2021, doi: 10.1021/acsnano.1c04996. 
[106] T. M. Allen and P. R. Cullis, "Liposomal drug delivery systems: From concept to clinical applications," Adv. Drug Deliv. Rev., vol. 65, no. 1, pp. 36-48, 2013, doi: https://doi.org/10.1016/j.addr.2012.09.037.

[107] X. Hou, T. Zaks, R. Langer, and Y. Dong, "Lipid nanoparticles for mRNA delivery," Nat. Rev. Mater., pp. 1-17, Aug. 2021, doi: 10.1038/s41578-021-00358-0.

[108] M. K. Riaz et al., "Surface Functionalization and Targeting Strategies of Liposomes in Solid Tumor Therapy: A Review," Int. J. Mol. Sci., vol. 19, no. 1, p. 195, Jan. 2018, doi: 10.3390/ijms19010195.

[109] R. J. Bingham, P. D. Olmsted, and S. W. Smye, “Undulation instability in a bilayer lipid membrane due to electric field interaction with lipid dipoles," Phys. Rev. E, vol. 81, no. 5, p. 51909, May 2010, doi: 10.1103/PhysRevE.81.051909.

[110] X. Y. Wang, T. Ishida, M. Ichihara, and H. Kiwada, "Influence of the physicochemical properties of liposomes on the accelerated blood clearance phenomenon in rats," J. Control. Release, vol. 104, no. 1, pp. 91-102, 2005, doi: https://doi.org/10.1016/j.jconrel.2005.01.008.

[111] G. Liu et al., "A Review on Drug Delivery System for Tumor Therapy , , Frontiers in Pharmacology , vol. 12. p. 2294, 2021, [Online]. Available: https://www.frontiersin.org/article/10.3389/fphar.2021.735446.

[112] S. Deodhar and A. K. Dash, “Long circulating liposomes: challenges and opportunities,” Ther. Deliv., vol. 9, no. 12, pp. 857-872, Nov. 2018, doi: 10.4155/tde-2018-0035.

[113] S. R. Benhabbour et al., "In vitro and in vivo assessment of targeting lipid-based nanoparticles to the epidermal growth factor-receptor (EGFR) using a novel Heptameric ZEGFR domain," J. Control. Release, vol. 158, no. 1, pp. 63-71, Feb. 2012, doi: 10.1016/j.jconrel.2011.10.013.

[114] G. T. Noble, J. F. Stefanick, J. D. Ashley, T. Kiziltepe, and B. Bilgicer, “Ligand-targeted liposome design: challenges and fundamental considerations," Trends Biotechnol., vol. 32, no. 1, pp. 32-45, 2014, doi: https://doi.org/10.1016/j.tibtech.2013.09.007.

[115] K. Wang et al., "Protein liposomes-mediated targeted acetylcholinesterase gene delivery for effective liver cancer therapy," J. Nanobiotechnology, vol. 19, no. 1, p. 31, 2021, doi: 10.1186/s12951-021-00777-9.

[116] S. Deodhar, A. K. Dash, E. J. North, and M. Hulce, “Development and In Vitro Evaluation of Long Circulating Liposomes for Targeted Delivery of Gemcitabine and Irinotecan in Pancreatic Ductal Adenocarcinoma," AAPS PharmSciTech, vol. 21, no. 6, p. 231, 2020, doi: 10.1208/s12249-020-01745-6.

[117] G. Blume and G. Cevc, "Liposomes for the sustained drug release in vivo," Biochim. Biophys. Acta - Biomembr., vol. 1029, no. 1, pp. 91-97, 1990, doi: https://doi.org/10.1016/0005-2736(90)90440-Y.

[118] A. L. Klibanov, K. Maruyama, V. P. Torchilin, and L. Huang, "Amphipathic polyethyleneglycols effectively prolong the circulation time of liposomes," FEBS Lett., vol. 268, no. 1, pp. 235-237, Jul. 1990, doi: https://doi.org/10.1016/0014-5793(90)81016-H.

[119] D. dos S. Ferreira, S. C. de A. Lopes, M. S. Franco, and M. C. Oliveira, "pH-sensitive liposomes for drug delivery in cancer treatment," Ther. Deliv., vol. 4, no. 9, pp. 1099-1123, Sep. 2013, doi: 10.4155/tde.13.80.

[120] M. Abri Aghdam et al., "Recent advances on thermosensitive and pH-sensitive liposomes employed in controlled release," J. Control. Release, vol. 315, pp. 1-22, 2019, doi: https://doi.org/10.1016/j.jconrel.2019.09.018.

[121] M. Kanamala, B. D. Palmer, S. M. F. Jamieson, W. R. Wilson, and Z. Wu, “Dual pH-sensitive liposomes with low pH-triggered sheddable PEG for enhanced tumor-targeted drug delivery," Nanomedicine, vol. 14, no. 15, pp. 1971-1989, Jul. 2019, doi: 10.2217/nnm-2018-0510.

[122] Z.-Y. He et al., “In Vivo Ovarian Cancer Gene Therapy Using CRISPR-Cas9,” Hum. Gene Ther., vol. 29, no. 2, pp. 223-233, Jan. 2018, doi: 10.1089/hum.2017.209.

[123] M. Zhang et al., "Liposome mediated-CYP1A1 gene silencing nanomedicine prepared using lipid film-coated proliposomes as a potential treatment strategy of lung cancer," Int. J. Pharm., vol. 566, pp. 185-193, 2019, doi: 
https://doi.org/10.1016/j.ijpharm.2019.04.078.

[124] P. Moitra et al., "Cancer Stem Cell-Targeted Gene Delivery Mediated by Aptamer-Decorated pH-Sensitive Nanoliposomes," ACS Biomater. Sci. Eng., vol. 7, no. 6, pp. 2508-2519, Jun. 2021, doi: 10.1021/acsbiomaterials.1c00110.

[125] J. Pei et al., “Combination with liposome-entrapped, ends-modified raf antisense oligonucleotide (LErafAON) improves the anti-tumor efficacies of cisplatin, epirubicin, mitoxantrone, docetaxel and gemcitabine," Anticancer. Drugs, vol. 15, no. 3, 2004, [Online]. Available: https://journals.lww.com/anticancerdrugs/Fulltext/2004/03000/Combination_with_liposome_entrapped,_ends_modified.9.aspx.

[126] D. Li, F. Guo, K. Chen, X. Yang, and Y. Wang, "Preclinical Safety Evaluation of a Recombinant Plasmid Vector Encoding Mature Human Neutrophil Peptide-1 by Repeated Local Administrations in Nonhuman Primates," Hum. Gene Ther., vol. 32, no. 21-22, pp. 1382-1389, Apr. 2021, doi: 10.1089/hum.2020.289.

[127] C. F. Bennett, “Therapeutic Antisense Oligonucleotides Are Coming of Age," Annu. Rev. Med., vol. 70, no. 1, pp. 307-321, Jan. 2019, doi: 10.1146/annurev-med-041217-010829.

[128] R. M. Conry et al., "Characterization of a Messenger RNA Polynucleotide Vaccine Vector," Cancer Res., vol. 55, no. $7, \quad$ pp. 1397 LP $\quad-\quad 1400$, Apr. 1995, [Online]. Available: http://cancerres.aacrjournals.org/content/55/7/1397.abstract.

[129] U. Sahin et al., "Personalized RNA mutanome vaccines mobilize poly-specific therapeutic immunity against cancer," Nature, vol. 547, no. 7662, pp. 222-226, 2017, doi: 10.1038/nature23003.

[130] H. A. Burris et al., "A phase I multicenter study to assess the safety, tolerability, and immunogenicity of mRNA4157 alone in patients with resected solid tumors and in combination with pembrolizumab in patients with unresectable solid tumors.," J. Clin. Oncol., vol. 37, no. 15_suppl, p. 2523, May 2019, doi: 10.1200/JCO.2019.37.15_suppl.2523.

[131] S. H. Kiaie et al., "Axial pharmaceutical properties of liposome in cancer therapy: Recent advances and perspectives," Int. J. Pharm., vol. 581, p. 119269, 2020, doi: https://doi.org/10.1016/j.ijpharm.2020.119269.

[132] G. Ozcan, B. Ozpolat, R. L. Coleman, A. K. Sood, and G. Lopez-Berestein, "Preclinical and clinical development of siRNA-based therapeutics," Adv. Drug Deliv. Rev., vol. 87, pp. 108-119, Jun. 2015, doi: 10.1016/j.addr.2015.01.007.

[133] L. Ciani, S. Ristori, A. Salvati, L. Calamai, and G. Martini, "DOTAP/DOPE and DC-Chol/DOPE lipoplexes for gene delivery: zeta potential measurements and electron spin resonance spectra," Biochim. Biophys. Acta Biomembr., vol. 1664, no. 1, pp. 70-79, 2004, doi: https://doi.org/10.1016/j.bbamem.2004.04.003.

[134] J. Halder et al., "Focal adhesion kinase targeting using in vivo short interfering RNA delivery in neutral liposomes for ovarian carcinoma therapy," Clin. Cancer Res., vol. 12, no. 16, pp. 4916-4924, Aug. 2006, doi: 10.1158/1078-0432.CCR-06-0021.

[135] M. J. Gray et al., “Therapeutic Targeting of Neuropilin-2 on Colorectal Carcinoma Cells Implanted in the Murine Liver," JNCI J. Natl. Cancer Inst., vol. 100, no. 2, pp. 109-120, Jan. 2008, doi: 10.1093/jnci/djm279.

[136] I. Tekedereli et al., "Therapeutic Silencing of Bcl-2 by Systemically Administered siRNA Nanotherapeutics Inhibits Tumor Growth by Autophagy and Apoptosis and Enhances the Efficacy of Chemotherapy in Orthotopic Xenograft Models of ER (-) and ER (+) Breast Cancer," Mol. Ther. Nucleic Acids, vol. 2, no. 9, pp. e121-e121, Sep. 2013, doi: 10.1038/mtna.2013.45.

[137] M. Gallarate, M. Trotta, L. Battaglia, and D. Chirio, "Preparation of solid lipid nanoparticles from W/O/W emulsions: Preliminary studies on insulin encapsulation," J. Microencapsul., vol. 26, no. 5, pp. 394-402, Aug. 2009, doi: 10.1080/02652040802390156.

[138] V. Wiedenmann, K. Oehlke, U. van der Schaaf, H. M. Koivula, K. S. Mikkonen, and H. P. Karbstein, “Emulsifier 
Composition of Solid Lipid Nanoparticles (SLN) Affects Mechanical and Barrier Properties of SLN-Protein Composite Films," J. Food Sci., vol. 84, no. 12, pp. 3642-3652, Dec. 2019, doi: https://doi.org/10.1111/17503841.14950 .

[139] T. Kaur and R. Slavcev, “Solid Lipid Nanoparticles: Tuneable Anti-Cancer Gene/Drug Delivery Systems,” 2013.

[140] H. Weyhers, S. Ehlers, H. Hahn, E. B. Souto, and R. Müller, "Solid lipid nanoparticles (SLN) - Effects of lipid composition on in vitro degradation and in vivo toxicity," Pharmazie, vol. 61, pp. 539-544, Jul. 2006.

[141] T. S. Zimmermann et al., "RNAi-mediated gene silencing in non-human primates," Nature, vol. 441, no. 7089, pp. 111-114, 2006, doi: 10.1038/nature04688.

[142] H. R. Kim, I. K. Kim, K. H. Bae, S. H. Lee, Y. Lee, and T. G. Park, “Cationic Solid Lipid Nanoparticles Reconstituted from Low Density Lipoprotein Components for Delivery of siRNA," Mol. Pharm., vol. 5, no. 4, pp. 622-631, Aug. 2008, doi: 10.1021/mp8000233.

[143] M. Mirahadi, S. Ghanbarzadeh, M. Ghorbani, A. Gholizadeh, and H. Hamishehkar, "A review on the role of lipid-based nanoparticles in medical diagnosis and imaging," Ther. Deliv., vol. 9, no. 8, pp. 557-569, Aug. 2018, doi: 10.4155/tde-2018-0020.

[144] T. T. H. Thi, E. J. A. Suys, J. S. Lee, D. H. Nguyen, K. D. Park, and N. P. Truong, “Lipid-Based Nanoparticles in the Clinic and Clinical Trials: From Cancer Nanomedicine to COVID-19 Vaccines," Vaccines, vol. 9, no. 4, p. 359, Apr. 2021, doi: 10.3390/vaccines9040359.

[145] Y. Liu et al., "A Fully Integrated Online Platform For Real Time Monitoring Of Multiple Product Quality Attributes In Biopharmaceutical Processes For Monoclonal Antibody Therapeutics," J. Pharm. Sci., 2021, doi: https://doi.org/10.1016/j.xphs.2021.09.011.

[146] M. Patel et al., "The Immunopathobiology of SARS-CoV-2 Infection," FEMS Microbiol. Rev., vol. 45, no. 6, p. fuab035, Nov. 2021, doi: 10.1093/femsre/fuab035. 